Original

\title{
High Susceptibility to Zymbal Gland and Intestinal Carcinogenesis in Diabetic Otsuka Long-Evans Tokushima Fatty Rats
}

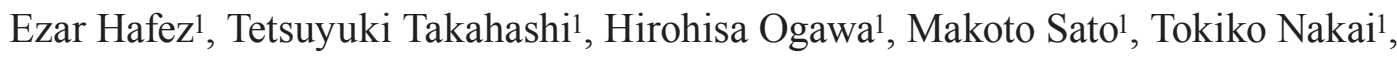 \\ Chie Takasu', Hisanori Uehara ${ }^{1}$, and Keisuke Izumi ${ }^{1}$ \\ ${ }^{1}$ Department of Molecular and Environmental Pathology, Institute of Health Biosciences, The University of Tokushima \\ Graduate School, 3-18-15 Kuramoto-cho, Tokushima 770-8503, Japan
}

\begin{abstract}
Diabetes mellitus (DM) and obesity are believed to be risk factors for colorectal cancer in humans. In experiment 1, male nondiabetic Long-Evans Tokushima Otsuka (LETO) rats and Otsuka Long-Evans Tokushima Fatty (OLETF) rats, a model animal of type 2 DM, were whole-body X-irradiated (4 Gy) at 6 and 8 weeks of age and euthanized at 78 weeks of age $(\mathrm{n}=15$, respectively). The incidences of small intestine adenocarcinoma in LETO and OLETF rats were $0 \%$ and $30 \%$, respectively. In experiment 2 , male LETO and OLETF rats ( $\mathrm{n}=24$, respectively) were given s.c. injections of $15 \mathrm{mg} / \mathrm{kg}$ azoxymethane (AOM) once weekly for 3 weeks and euthanized at 36 weeks of age. The incidences of Zymbal gland tumors in LETO and OLETF rats were $0 \%$ and $67 \%$, respectively $(P<0.001)$, whereas those of small intestine adenocarcinoma were $0 \%$ and $43 \%(P<0.001)$ and those of cecum/colon adenocarcinoma were $46 \%$ and $79 \%(P<0.05)$, respectively. Fatty change of hepatocytes was common in OLETF rats $(63 \%)$ but not in LETO rats. Serum triglyceride and free fatty acid levels in OLETF rats were significantly higher than in LETO rats at sacrifice, whereas serum insulin levels in OLETF rats were very diverse. These data suggest that hyperlipidemia plays a significant role in high susceptibility to lower intestinal tract carcinogenesis in OLETF rats; this strain is susceptible to AOM-induced Zymbal gland carcinogenesis. (DOI: 10.1293/tox.24.187; J Toxicol Pathol 2011; 24: 187-193)
\end{abstract}

Key words: OLETF rat, carcinogenesis, zymbal gland, colon, hyperlipidemia

\section{Introduction}

Epidemiologic studies have suggested a positive link between diabetes mellitus (DM) and various neoplasms including colon cancer $^{1,2}$. Obesity is a risk factor for DM and cancer of various organs including the colon ${ }^{3,4}$. Insulin resistance, chronic inflammation and/or altered adipokine secretion with resultant hyperlipidemia may be involved in DM and obesity-related cancer ${ }^{5}$. Exogenous insulin use may also be a risk factor for colorectal cancer6.

Otsuka Long-Evans Tokushima Fatty (OLETF) rats?

Received: 10 June 2011, Accepted: 30 June 2011

Mailing address: Keisuke Izumi, Department of Molecular and Environmental Pathology, Institute of Health Biosciences, The University of Tokushima Graduate School, 3-18-15 Kuramoto-cho, Tokushima 770-8503, Japan

TEL: 81-88-633-7065 FAX: 81-88-633-7067

E-mail: izumi@basic.med.tokushima-u.ac.jp

(C2011 The Japanese Society of Toxicologic Pathology

This is an open-access article distributed under the terms of the Creative Commons Attribution Non-Commercial No Derivatives (by-ncnd) License $<$ http://creativecommons.org/licenses/by-nc-nd/3.0/>. established from a closed colony of Long-Evans rats by selective breeding along with nondiabetic Long-Evans Tokushima Otsuka (LETO) rats, are a model animal of type $2 \mathrm{DM}$ and show late conversion to insulin-dependent disease. This strain has mild obesity, and a homozygous deletion in cholecystokinin-1 (CCK1) receptor gene responsible for hyperphagia has been identified ${ }^{8,9}$. OLETF rats are susceptible to $N$-nitrosobis(2-oxopropyl)amine-induced thyroid carcinogenesis ${ }^{10}$. In the present study, we examined $\mathrm{X}$-irradiation and azoxymethane (AOM)-induced carcinogenesis in LETO and OLETF rats.

\section{Materials and Methods}

\section{Animals}

LETO and OLETF rats were obtained from Otsuka Pharmaceutical Co., Ltd., Tokushima, Japan. Animals were housed three to a plastic cage with sterilized woodchips for bedding in an air-conditioned room at $23 \pm 2{ }^{\circ} \mathrm{C}$ and $55 \pm$ $10 \%$ humidity with a 12 -h light/dark cycle and given pellet diet (Oriental MF; Oriental Yeast Co., Ltd., Tokyo, Japan) and tap water ad libitum. Experiments were conducted according to the Guidelines for the Care and Use of Laborato- 


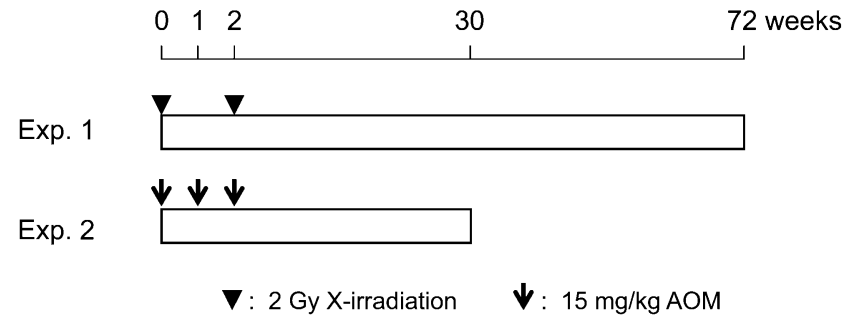

Fig. 1. Experimental design for $\mathrm{X}$-irradiation and AOM-induced carcinogenesis.

ry Animals of the University of Tokushima, and the experimental protocol was approved by the Animal Committee.

\section{Carcinogenicity study}

Experiment 1: After a 1-week acclimation period, sixweek-old male LETO and OLETF rats ( $\mathrm{n}=15$, respectively) were whole-body X-irradiated (4 Gy) at 6 and 8 weeks of age (Fig. 1). Three animals were put into an acrylic resin box and irradiated at a dose rate of $1.54 \mathrm{~Gy} / \mathrm{min}$ using an X-ray irradiation system (Hitachi MBR-1520R-3; Hitachi Medical Corporation, Tokyo, Japan). Control animals ( $n=15$, respectively) were maintained for approximately $2 \mathrm{~min}$ in the chamber without irradiation (sham-irradiated). Body weight was monitored every other week, and all animals were euthanized at 78 weeks of age under carbon dioxide narcosis. The stomach and intestine were opened, and the size and location of tumors were recorded; the tumors were then fixed in $10 \%$ buffered formalin and embedded in paraffin. For histological examination, tissue sections were stained with hematoxylin and eosin. Other major organs were also examined histologically. At 12 and 42 weeks of age, control rats were submitted to an oral glucose tolerance test (OGTT) after 16-h fasting in experiment $1(\mathrm{n}=9)$. Glucose (Wako Pure Chemical Industries, Ltd., Osaka, Japan) was given by gavage, $2 \mathrm{~g} / \mathrm{kg}$ body weight, at about $10 \mathrm{a} . \mathrm{m}$. Blood was collected from the tail. Thirty-minute postglucose load blood glucose was measured by the glucose oxidase method. Serum insulin was measured using an ELISA kit (Morinaga Institute of Biological Science, Yokohama, Japan).

Experiment 2: AOM was purchased from Wako Pure Chemical Industries, Ltd. Six-week-old male LETO and OLETF rats $(n=24$, respectively) were given s.c. injections of $\mathrm{AOM}$ at a dose of $15 \mathrm{mg} / \mathrm{kg}$ body weight once weekly for 3 weeks (Fig. 1). AOM was dissolved in $0.9 \% \mathrm{NaCl}$ just before use. Animals were euthanized at 36 weeks of age. Blood samples were collected from the inferior vena cava at sacrifice $(n=9$, respectively), and the serum to examine insulin, triglyceride, free fatty acid and total cholesterol was frozen at $-30{ }^{\circ} \mathrm{C}$ until use. Serum lipids were measured by SRL Inc., Tokyo, Japan. Histological examination of organs including neoplasms was performed.

\section{Quantitative real-time RT-PCR}

Livers from untreated 24-week-old male LETO and OLETF rats ( $\mathrm{n}=5$, respectively) were stabilized with RNAlater (Applied Biosystems, Carlsbad, CA, USA) at $4{ }^{\circ} \mathrm{C}$ overnight and then total RNAs were isolated using an RNeasy ${ }^{\circledR}$ Mini Kit (QIAGEN, Valencia, CA, USA). By using 1- $\mu$ g aliquots, cDNAs were synthesized with SuperScript II reverse transcriptase and random hexamers (Invitrogen, Carlsbad, CA, USA). Reactions were conducted at $42{ }^{\circ} \mathrm{C}$ for $60 \mathrm{~min}$, and then the temperature was increased to $72{ }^{\circ} \mathrm{C}$ for $15 \mathrm{~min}$. The total cDNAs were then subjected to quantitative real-time RT-PCR (qRT-PCR) by the comparative $\mathrm{Ct}$ method. Each sample was mixed with SYBR Premix Ex Taq II (Takara Bio, Shiga, Japan) and specific primers for insulin-like growth factor (IGF)-1, plasminogen activator inhibitor (Pai)-1 and $\beta$-actin, according to the manufacturer's guidelines. $\beta$-Actin was used as an internal standard. These samples were then amplified using a 7500 Real-time PCR System (Applied Biosystems), and the data were analyzed with 7500 System SDS software (Applied Biosystems). Thermocycling program was as follows: $95^{\circ} \mathrm{C}$ for $30 \mathrm{~s}$ for initial denaturation and 40 cycles of $95^{\circ} \mathrm{C}$ for $5 \mathrm{~s}$ and $60{ }^{\circ} \mathrm{C}$ for $34 \mathrm{~s}$ for amplification. The sequences of the primers were as follows: IGF-1-F, 5'-TTCAGTTCGTGTGTGGACCAAG-3'; IGF-1-R, 5'-GATCACAGCTCCGGAAGCAA-3'; Pai-1-F, 5'-GCCCAGCATTCAGCCTTTG-3'; Pai-1-R, 5'-AAGACTTTGCTGAGTGAAGGCGTAG-3'; $\beta$-actin-F, 5'-GGAGATTACTGCCCTGGCTCCTA-3'; and $\beta$-actin-R, 5'-GACTCATCGTACTCCTGCTTGCTG-3'.

\section{Measurement of food intake}

Male LETO and OLETF rats were given pellet diet, and food intake and body weight were monitored every other week until 20 weeks of age $(n=15$, respectively).

\section{Statistical analyses}

The incidence of tumors was analyzed by Fisher's exact probability test; other data were analyzed by two-tailed Student's $t$-test.

\section{Results}

\section{Experiment 1}

The Average body weight of X-irradiated OLETF rats was found to be increased at sacrifice because of huge soft tissue sarcomas in some rats (Fig. 2). X-irradiation increased the incidence of various tumors in both strains (Table 1). Small intestinal adenocarcinomas developed in 3 OLETF rats $(30 \%)$, but not in LETO rats. The colonic tumor in the X-irradiated OLETF rat was a leiomyosarcoma. $\mathrm{X}$-irradiation caused a low incidence of islet cell tumors in both strains. Hyperglycemia at 12 and 42 weeks of age and hyperinsulinemia at 42 weeks of age were observed in control OLETF rats (Fig. 3). X-irradiation increased blood glucose levels and reduced insulin levels in OLETF rats compared with the control at 42 weeks of age, although not significantly, whereas these parameters were not affected by 
Table 1. Incidence of Tumors in 4-Gy X-irradiated Male LETO and OLETF Rats

\begin{tabular}{|c|c|c|c|c|c|c|c|}
\hline \multirow[b]{2}{*}{ Strain } & \multirow[b]{2}{*}{$\begin{array}{l}\text { No. of } \\
\text { rats }\end{array}$} & \multicolumn{6}{|c|}{ Tumors } \\
\hline & & Lung & Kidney & $\begin{array}{l}\text { Small } \\
\text { intestine }\end{array}$ & Colon & $\begin{array}{l}\text { Pancreatic } \\
\text { islet }\end{array}$ & $\begin{array}{l}\text { Soft } \\
\text { tissue }\end{array}$ \\
\hline \multicolumn{8}{|c|}{ Sham-irradiated } \\
\hline LETO & 15 & 0 & 0 & 0 & 0 & 0 & $1(7 \%)$ \\
\hline OLETF & 15 & 0 & 0 & 0 & 0 & 0 & $1(7 \%)$ \\
\hline \multicolumn{8}{|c|}{ 4-Gy X-irradiated } \\
\hline LETO & $13^{\mathrm{a}}$ & 0 & $5(38 \%)$ & 0 & 0 & $1(8 \%)$ & $7(54 \%)$ \\
\hline OLETF & $10^{\mathrm{b}}$ & $2(20 \%)$ & $3(30 \%)$ & $3(30 \%)$ & $1(10 \%)$ & $3(30 \%)$ & $4(40 \%)$ \\
\hline
\end{tabular}

a Two rats died of unknown cause at 24 and 45 weeks of age. b Four rats died of severe diabetes at 12, 12, 13 and 20 weeks of age, and one rat died accidentally at 42 weeks of age.

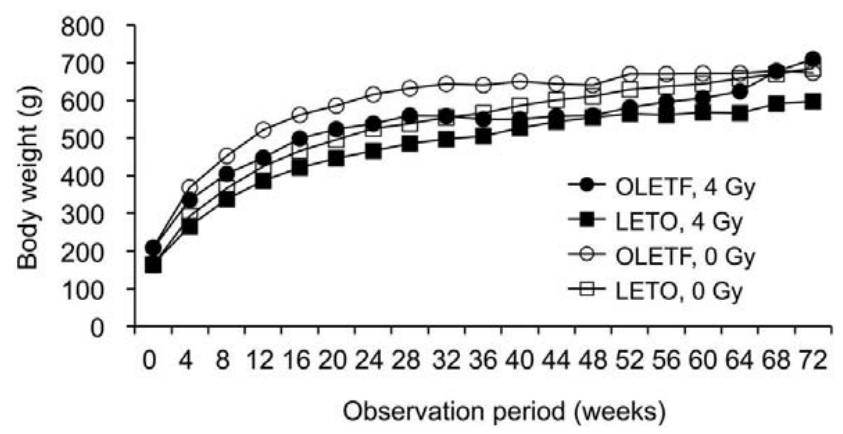

Fig. 2. Growth curves of male LETO and OLETF rats in X-irradiation-induced carcinogenesis.

\section{A}
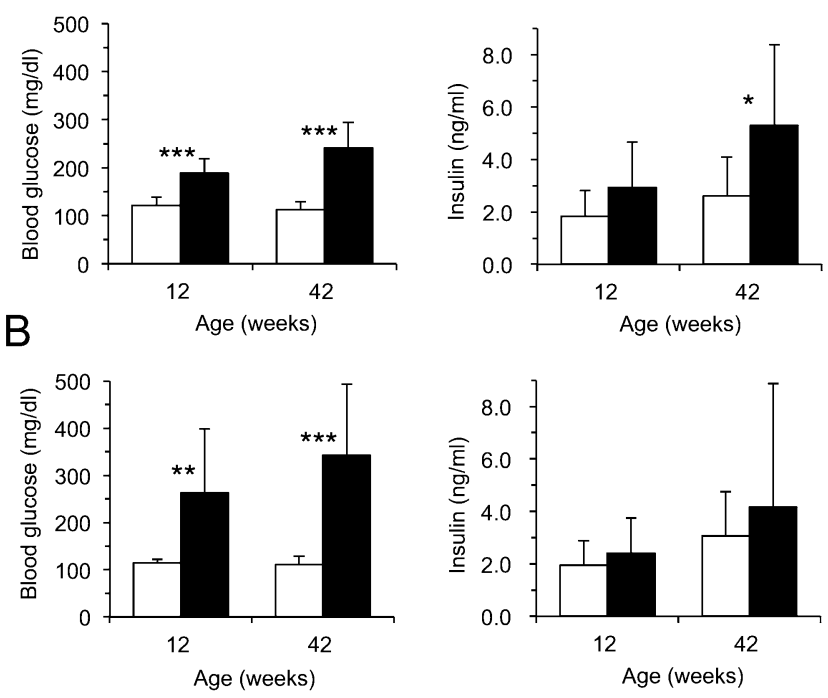

Fig. 3. Average blood glucose and serum insulin levels in LETO and OLETF rats at 12 and 42 weeks of age in an oral $2 \mathrm{~g} / \mathrm{kg}$ OGTT (experiment 1). A, sham-irradiated rats; B, X-irradiated (4 Gy) rats. * ** and ***; $P<0.05, P<0.01$ and $P<0.001$, respectively, versus LETO rat (two-tailed Student's $t$-test). $\square$, LETO rat; $\mathbf{n}$, OLETF rat; Bars, SD.

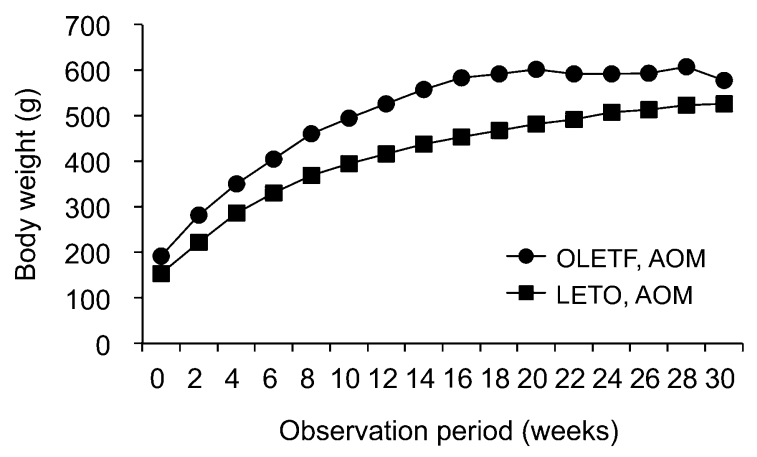

Fig. 4. Growth curves of male LETO and OLETF rats in AOM-induced carcinogenesis.

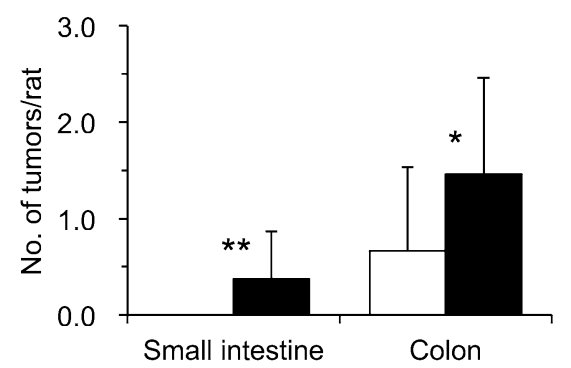

Fig. 5. Average no. of small intestine and colon tumors in LETO and OLETF rats (experiment 2). The average no. of colon tumors in OLETF rats was 2.1 times higher than in LETO rats. * and **; $P<0.01$ and $P<0.001$, respectively, versus LETO rats (two-tailed Student's $t$-test). $\square$, LETO rat; $\mathbf{m}$, OLETF rat; Bars, SD.

$\mathrm{X}$-irradiation in LETO rats.

\section{Experiment 2}

The average body weight of OLETF rats was higher than that of LETO rats throughout the experimental period (Fig. 4). The incidence of Zymbal gland, small intestine and colon tumors in OLETF rats was significantly higher than in LETO rats (Table 2). Malignant lymphoma developed in one LETO rat, but no other tumors developed in either strain. 

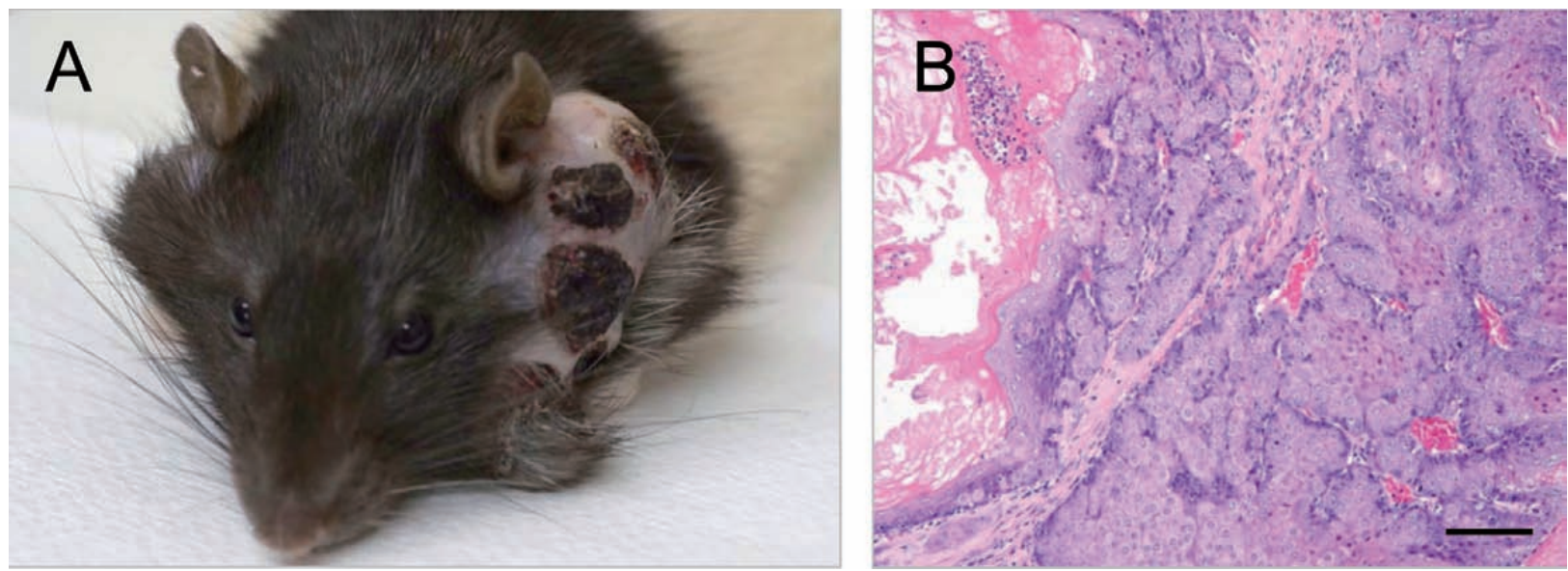

Fig. 6. AOM-induced Zymbal gland tumors in OLETF rats. A, bilateral Zymbal gland tumors in an OLETF rat; B, sebaceous carcinoma of the Zymbal gland. Bar, $100 \mu \mathrm{m}$.
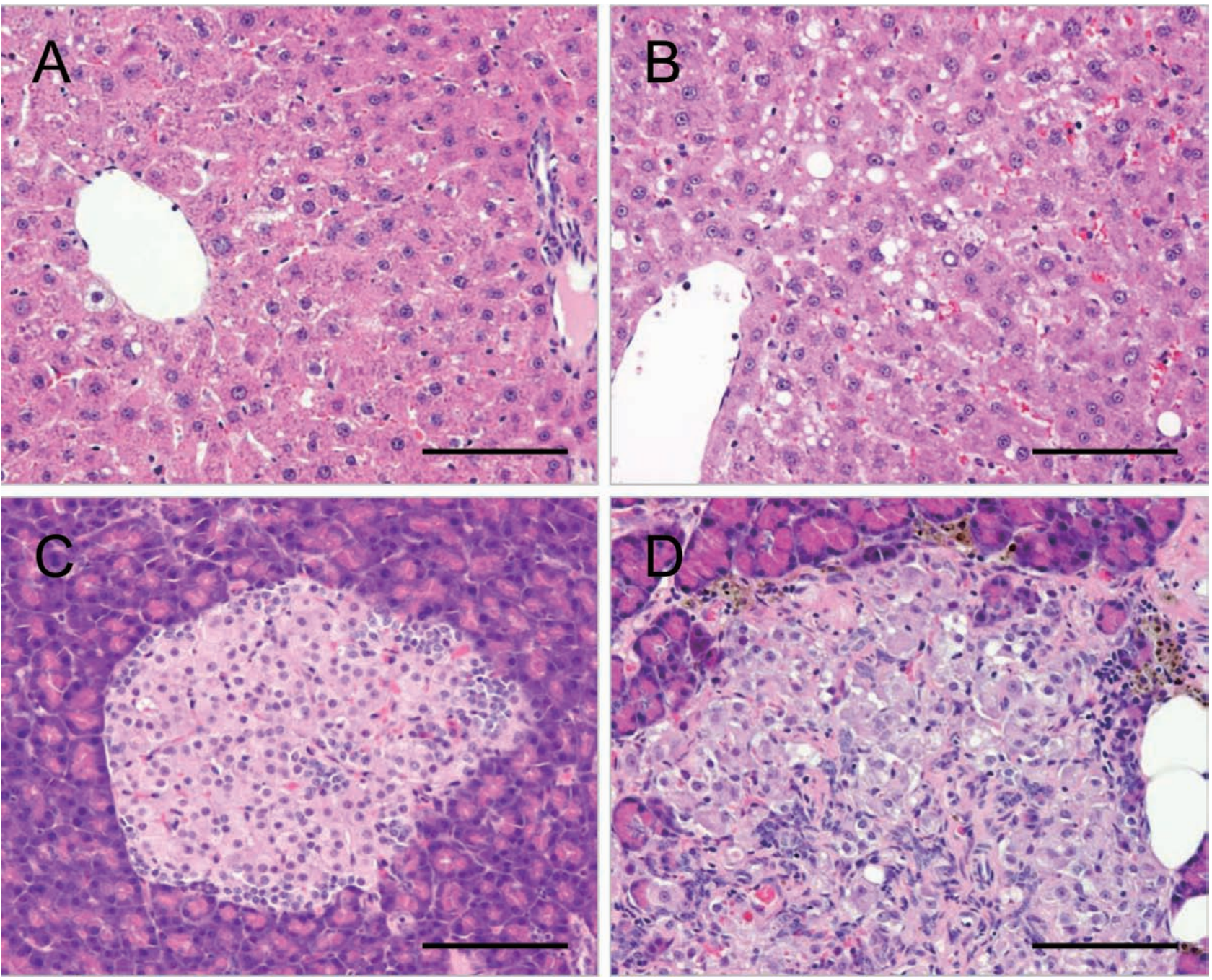

Fig. 7. Histological appearance of AOM-treated LETO and OLETF rats (experiment 2). A, liver of a LETO rat; B, liver of an OLETF rat; C, pancreatic islets of a LETO rat; D, pancreatic islets of an OLETF rat. Bars, $100 \mu \mathrm{m}$. 
Table 2. Incidence of AOM-induced Tumors in Male LETO and OLETF Rats

\begin{tabular}{lllll}
\hline \multirow{2}{*}{ Strain } & $\begin{array}{l}\text { No. of } \\
\text { rats }\end{array}$ & Zymbal gland & Small intestine & Colon \\
\cline { 3 - 5 } & 24 & 0 & 0 & $11(46 \%)$ \\
LETO & $24^{\mathrm{a}}$ & $16(67 \%)^{* * *}$ & $9(38 \%)^{* *}$ & $19(79 \%)^{* *}$ \\
\hline
\end{tabular}

${ }^{a}$ One rat died of colonic and Zymbal gland tumors at 20 weeks of age. Five rats were euthanized at 29, 31, 32, 33 and 34 weeks of age due to colonic and/or Zymbal gland tumors. *, ** and ***; $P<0.05, P<0.01$ and $P<0.001$, respectively, versus LETO rats (Fisher's exact probability test).

A

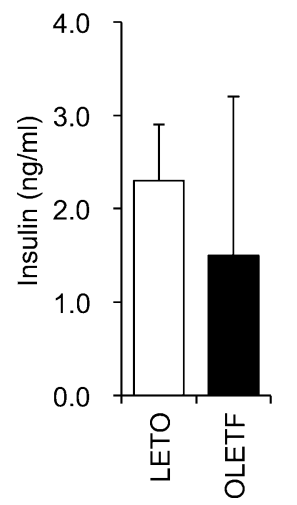

B

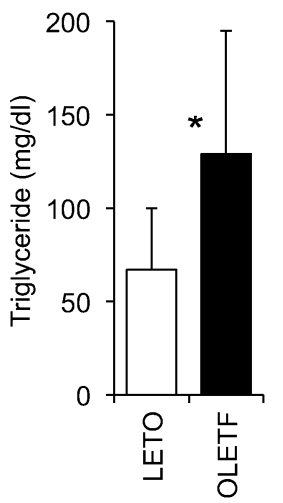

C

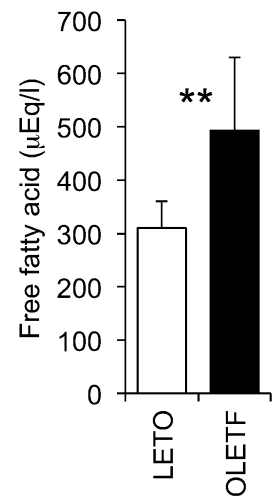

D

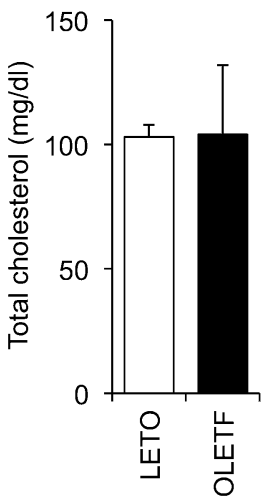

Fig. 8. Serum insulin, triglyceride, free fatty acid and total cholesterol in LETO and OLETF rats at 36 weeks of age (experiment 2). * and **; $P<0.05$ and $P<0.01$, respectively, versus LETO rats (two-tailed Student's $t$-test). A, insulin; B, triglyceride; C, free fatty acid; D, total cholesterol. $\square$, LETO rat; $\mathbf{m}$, OLETF rat; Bars, SD.

IGF-1

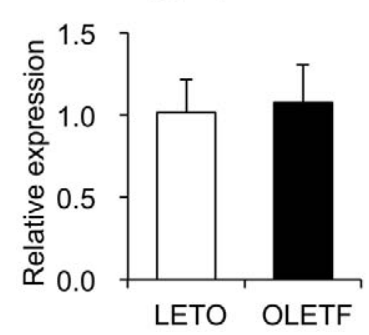

Fig. 9. Expression of IGF-1 and Pai-1 mRNA in the liver of LETO and OLETF rats $(n=5)$. Relative expression levels of IGF-1 and Pai-1 mRNA were detected by qRT-PCR. Bars, SD.

The average numbers of small intestine and colon tumors in OLETF rats were higher than in LETO rats (Fig. 5). These tumors were mainly tubular adenocarcinoma histologically, and signet-ring cell carcinoma developed in one LETO rat. In one OLETF rat, colonic cancer metastasized to a retroperitoneal lymph node. Six of the 16 Zymbal gland tumors in OLETF rats, sebaceous carcinoma histologically, were bilateral (Fig. 6). The incidence of fatty change of hepatocytes was 15/24 (63\%) in OLETF rats and $0 \%$ in LETO rats (Fig. 7). Pancreatic islets of OLETF rats showed hemosiderosis, loss of islet cells and fibrosis. The average serum insulin

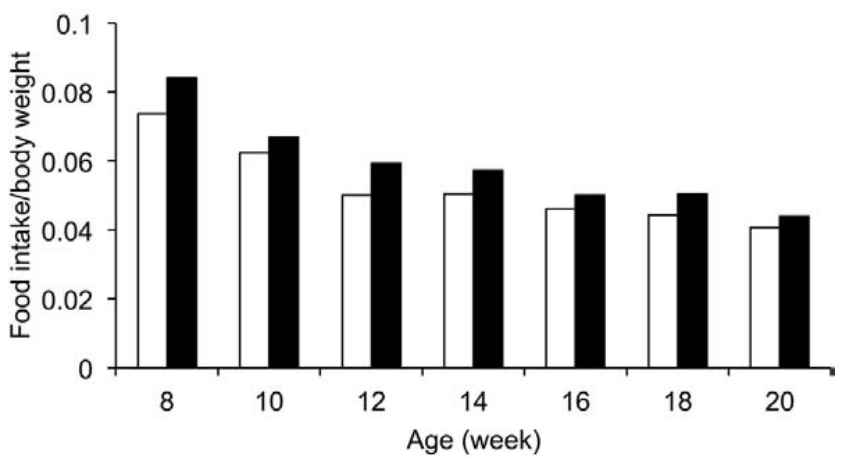

Fig. 10. Food intake/body weight ratio in LETO and OLETF rats. $\square$, LETO rat; $\mathbf{n}$, OLETF rat.

level in OLETF rats was lower than in LETO rats (Fig. 8). The insulin levels in 2 of 9 OLETF rats were higher than the maximum value in LETO rats, but those in 5 OLETF rats were lower than the minimum value in LETO rats. Serum triglyceride and free fatty acid levels in OLETF rats were significantly higher than in LETO rats at sacrifice.

\section{Analysis of the liver}

The relative expression levels of liver IGF-1 and Pai-1 mRNA in OLETF rats were 1.08 \pm 0.23 -fold and $1.63 \pm 0.45$ - 
fold, respectively, those in LETO rats. No significant differences were observed between the strains (Fig. 9).

\section{Food intake}

The average food intakes of the untreated LETO and OLETF rats were $18.5 \mathrm{~g}$ and $26.0 \mathrm{~g}$, respectively. The food intake/body weight ratio in OLETF rats was 1.08-1.19 times higher than in LETO rats (Fig. 10).

\section{Discussion}

$\mathrm{X}$-irradiation induced a low incidence of intestinal cancer in OLETF rats, but not in LETO rats, and OLETF rats were clearly susceptible to AOM-induced Zymbal gland and lower intestinal tract carcinogenesis. Zucker obese rats, a model animal with leptin receptor gene mutation with hyperleptinemia, exhibit marked obesity and type $2 \mathrm{DM}^{11,12}$. Zucker obese rats are also more susceptible to AOM-induced colon cancer than control Zucker lean rats ${ }^{13,14}$ [REMOVED HYPERLINK FIELD]. The OLETF strain also shows hyperleptinemia, but there is no mutation in the leptin receptor gene ${ }^{15}$, and obesity is milder than in Zucker obese rats.

Hyperlipidemia is suggested to be an important factor for intestinal polyp formation in Apc-deficient mice from studies on suppression of hyperlipidemia by peroxisome proliferator-activated receptor- $\alpha$ and receptor- $\gamma$ agonists and by Pai-1 blockers ${ }^{16,17}$. In our recent study, $20 \%$ caloric restriction reduced serum triglyceride and inhibited both AOM-induced colonic and Zymbal gland neoplasms in OLETF rats (data not shown). Hence, the hyperlipidemic state in OLETF rats may play a significant role in high susceptibility to intestinal carcinogenesis. Insulin and IGF-1, growth factors in vitro, increase in obesity. It is reported that insulin promoted AOM-induced colon carcinogenesis in F344 rats $^{18}$. In the present experiments, the insulin levels in OLETF rats were diverse, and the hepatic IGF-1 mRNA level in OLETF rats was not different from that in LETO rats, suggesting that the role of hyperinsulinemia in carcinogenesis is not distinct. However, the role of insulin and the molecular mechanisms of adipose tissue dysfunction should be further investigated ${ }^{4,5}$.

The data for the insulin levels in the OGTT in experiment 1 and those without glucose load in experiment 2 were various. Although the measurement conditions were different, AOM treatment might reduce insulin levels.

The Zymbal gland, a sebaceous gland of the external ear canal, is a target organ of AOM in rats ${ }^{19,20}$. In the present study, Zymbal gland tumor developed at a high rate, 67\% in AOM-treated OLETF rats. However, in our recent study performed using the same protocol as the present study in nonobese Long-Evans Agouti rats ${ }^{21}$, a new model of type 2 $\mathrm{DM}$, the incidences of Zymbal gland, small intestine and colon tumors were $0 \%, 4 \%$ and $83 \%$, respectively (unpublished data). There is no description of Zymbal gland tumor in AOM-treated Zucker obese rats ${ }^{14}$. Therefore, the OLETF rat should be a strain susceptible to AOM-induced Zymbal gland carcinogenesis. It is known that both Zymbal glands and intestines in rats are target organs of heterocyclic amines in cooked foods such as 2-amino-3-methylimidazo[4,5-f]quinoline, 2-amino-6-methyldipyrido[1,2-a:3',2'-d]imidazole and 2-aminodipyrido[1,2-a:3',2'-d]imidazole 22 . In humans, the familial disease of sebaceous carcinoma plus visceral cancer including colorectal carcinoma is known as Muir-Torre syndrome 23 , a variant of hereditary nonpolyposis colorectal cancer. The mechanism of susceptibility to Zymbal gland carcinogenesis in OLETF rats should be elucidated.

In conclusion, the hyperphagic OLETF strain is a useful model for investigation of mechanisms of carcinogenesis and cancer prevention in diabetic conditions and obesity, and hyperlipidemia may play an important role in high susceptibility to Zymbal gland and intestinal carcinogenesis in OLETF rats.

Acknowledgments: We are grateful to Miss Hitomi Umemoto and Mrs. Megumi Sato for laboratory assistance.

\section{References}

1. Inoue M, Iwasaki M, Otani T, Sasazuki S, Noda M, and Tsugane S. Diabetes mellitus and the risk of cancer: results from a large-scale population-based cohort study in Japan. Arch Intern Med. 166: 1871-1877. 2006. [Medline] [CrossRef]

2. Limburg PJ, Vierkant RA, Fredericksen ZS, Leibson CL, Rizza RA, Gupta AK, Ahlquist DA, Melton LJ 3rd, Sellers TA, and Cerhan JR. Clinically confirmed type 2 diabetes mellitus and colorectal cancer risk: a population-based, retrospective cohort study. Am J Gastroenterol. 101: 18721879. 2006. [Medline] [CrossRef]

3. Renehan AG, Tyson M, Egger M, Heller RF, and Zwahlen M. Body-mass index and incidence of cancer: a systematic review and meta-analysis of prospective observational studies. Lancet. 371: 569-578. 2008. [Medline] [CrossRef]

4. van Kruijsdijk RC, van der Wall E, and Visseren FL. Obesity and cancer: the role of dysfunctional adipose tissue. Cancer Epidemiol Biomarkers Prev. 18: 2569-2578. 2009. [Medline] [CrossRef]

5. Hursting SD, Smith SM, Lashinger LM, Harvey AE, and Perkins SN. Calories and carcinogenesis: lessons learned from 30 years of calorie restriction research. Carcinogenesis. 31: 83-89. 2010. [Medline] [CrossRef]

6. Vinikoor LC, Long MD, Keku TO, Martin CF, Galanko JA, and Sandler RS. The association between diabetes, insulin use, and colorectal cancer among Whites and African Americans. Cancer Epidemiol Biomarkers Prev. 18: 12391242. 2009. [Medline] [CrossRef]

7. Kawano K, Hirashima T, Mori S, Saitoh Y, Kurosumi M, and Natori T. Spontaneous long-term hyperglycemic rat with diabetic complications. Otsuka Long-Evans Tokushima Fatty (OLETF) strain. Diabetes. 41: 1422-1428. 1992. [Medline] [CrossRef]

8. Funakoshi A, Miyasaka K, Shinozaki H, Masuda M, Kawanami T, Takata Y, and Kono A. An animal model of congenital defect of gene expression of cholecystokinin (CCK)A receptor. Biochem Biophys Res Commun. 210: 787-796. 1995. [Medline] [CrossRef] 
9. Takiguchi S, Takata Y, Funakoshi A, Miyasaka K, Kataoka K, Fujimura Y, Goto T, and Kono A. Disrupted cholecystokinin type-A receptor (CCKAR) gene in OLETF rats. Gene. 197: 169-175. 1997. [Medline] [CrossRef]

10. Sakano K, Takahashi M, Mutoh M, Niho N, Komiya M, Sato H, Tanaka T, Sugimura T, and Wakabayashi K. Enhanced thyroid carcinogenicity of N-nitrosobis(2-oxopropyl)amine in Otsuka Long-Evans Tokushima Fatty rats, a model of type II diabetes mellitus. Carcinogenesis. 28: 2193-2198. 2007. [Medline] [CrossRef]

11. Chua SC Jr, Chung WK, Wu-Peng XS, Zhang Y, Liu SM, Tartaglia L, and Leibel RL. Phenotypes of mouse diabetes and rat fatty due to mutations in the $\mathrm{OB}$ (leptin) receptor. Science. 271: 994-996. 1996. [Medline] [CrossRef]

12. Phillips MS, Liu Q, Hammond HA, Dugan V, Hey PJ, Caskey CJ, and Hess JF. Leptin receptor missense mutation in the fatty Zucker rat. Nat Genet. 13: 18-19. 1996. [Medline] [CrossRef]

13. Weber RV, Stein DE, Scholes J, and Kral JG. Obesity potentiates AOM-induced colon cancer. Dig Dis Sci. 45: 890895. 2000. [Medline] [CrossRef]

14. Jain SS, and Bird RP. Elevated expression of tumor necrosis factor-alpha signaling molecules in colonic tumors of Zucker obese (fa/fa) rats. Int J Cancer. 127: 2042-2050. 2010. [Medline] [CrossRef]

15. Moran TH, and Bi S. Hyperphagia and obesity in OLETF rats lacking CCK-1 receptors. Philos Trans R Soc Lond B Biol Sci. 361: 1211-1218. 2006. [Medline] [CrossRef]

16. Niho N, Takahashi M, Kitamura T, Shoji Y, Itoh M, Noda T, Sugimura T, and Wakabayashi K. Concomitant suppression of hyperlipidemia and intestinal polyp formation in Apcdeficient mice by peroxisome proliferator-activated receptor ligands. Cancer Res. 63: 6090-6095. 2003. [Medline]

17. Mutoh M, Niho N, Komiya M, Takahashi M, Ohtsubo R, Nakatogawa K, Ueda K, Sugimura T, and Wakabayashi K. Plasminogen activator inhibitor-1 (Pai-1) blockers suppress intestinal polyp formation in Min mice. Carcinogenesis. 29: 824-829. 2008. [Medline] [CrossRef]

18. Tran TT, Medline A, and Bruce WR. Insulin promotion of colon tumors in rats. Cancer Epidemiol Biomarkers Prev. 5: 1013-1015. 1996. [Medline]

19. Lijinsky W, Saavedra JE, and Reuber MD. Organ-specific carcinogenesis in rats by methyl- and ethylazoxyalkanes. Cancer Res. 45: 76-79. 1985. [Medline]

20. Lijinsky W, Thomas BJ, and Kovatch RM. Local and systemic carcinogenic effects of alkylating carcinogens in rats treated by intravesicular administration. Jpn J Cancer Res. 82: 980-986. 1991. [Medline]

21. Yoshida MC, Masuda R, Sasaki M, Takeichi N, Kobayashi $\mathrm{H}$, Dempo K, and Mori M. New mutation causing hereditary hepatitis in the laboratory rat. J Hered. 78: 361-365. 1987. [Medline]

22. Ohgaki H, Hasegawa H, Kato T, Suenaga M, Ubukata M, Sato S, Takayama S, and Sugimura T. Carcinogenicity in mice and rats of heterocyclic amines in cooked foods. Environ Health Perspect. 67: 129-134. 1986. [Medline] [CrossRef]

23. Ponti G, and Ponz de Leon M. Muir-Torre syndrome. Lancet Oncol. 6: 980-987. 2005. [Medline] [CrossRef] 